DOI 10.5216/ia.v46i3.67796

\title{
O PRETUGUÊSEM SALA DE AULA: RACISMO LINGUÍSTICO E AS PRÁTICAS PEDAGÓGICAS DA(O) DOCENTE DE LÍNGUA PORTUGUESA
}

\author{
LUCAS AndeRson NeVES de MeLo \\ Universidade Federal do Piauí (UFPI), Teresina, Piauí, Brasil \\ ane Patrícia Viana José de Mira \\ Universidade do Vale do Rio dos Sinos (UNISINOS), São Leopoldo, Rio Grande do Sul, \\ Brasil
}

\begin{abstract}
ReSUMO: O presente artigo aborda o tema das práticas pedagógicas docentes para o combate ao racismo nas aulas de língua portuguesa. Assim, objetivamos examinar as relações possíveis entre racismo linguístico e as práticas pedagógicas da(o) docente de Língua Portuguesa, com vistas à amenização e/ou superação dos mecanismos de exclusão raciolinguísticos no âmbito escolar. Pelo objetivo delineado, optamos pela pesquisa qualitativa, do tipo descritivo-explicativa, com uma abordagem narrativa, de viés decolonial. A discussão pretendida aponta para a necessidade de se repensar as políticas editoriais e públicas acerca dos livros didáticos; reorganizar o currículo escolar de forma a inserir efetivamente as temáticas sobre africanidades, afrodescendência e racialização nos conteúdos programáticos do ensino médio e reestruturar as políticas de currículo dos cursos de formação das(os) professoras(es) de Língua Portuguesa. Pois tais lacunas geram uma cumplicidade entre a educação escolar e o processo de silenciamento do pretuguês. A discussão ainda assinala a necessidade das(os) professoras(es) desenvolverem uma prática pedagógica reflexiva e ontológica em torno do problema do racismo linguístico.

Palavras-chaves: Educação para as Relações Étnico-raciais. Práticas Pedagógicas. Pretuguês. Racismo Linguístico.
\end{abstract}

\section{INTRODUÇÃO}

A educação brasileira tem sido perpassada nas últimas décadas por contínuas propostas que visam à promoção da igualdade étnico-racial no âmbito da Educação Básica, passando pela determinação de um currículo escolar que vise à superação das práticas pedagógicas curriculares excludentes, de modo a tensionar uma equalização dos direitos racializados e a desconstrução dos estereótipos e preconceitos, além do combate ao racismo em suas diversas manifestações.

Como exemplo dessas propostas temos a Lei №. 10.639, de 09 de janeiro de 2003 (BRASIL, 2003), que determina a obrigatoriedade do ensino sobre História e Cultura Afro-brasileira na Educação Básica. E também proposições como a Resolução №. 01, de 17 de junho de 2004 (BRASIL, 2004), que institui as Diretrizes Curriculares Nacionais para a Educação das Relações Étnico-Raciais e para o Ensino de História e Cultura Afrobrasileira e Africana, e a Lei №. 11.645, de 10 de março de 2008 (BRASIL, 2008), que altera a Lei № 10.639/2003, de modo a acrescer a obrigatoriedade do ensino de História a 
Cultura Indígena e Africana. No mesmo sentido, o Plano Nacional de Educação - PNE (Lei №. 13.005, de 25 de junho de 2014) determina em seu artigo $2^{\circ}$, inciso iii, a "superação das desigualdades educacionais, com ênfase na promoção da cidadania e na erradicação de todas as formas de discriminação" (BRASIL, 2014).

Diante deste contexto, as práticas pedagógicas das(os) docentes da Educação Básica assumem centralidade, na exata medida que é através delas que a escola pode tornar-se um espaço que legitime e valorize a diversidade, em vez de afirmar as diferenças pelas quais se nega a humanidade dos outros do Ocidente cristão. E mais do que isso, mediante a Educação, munir os educandos de um arsenal epistemológico antirracista. Porém, é demasiado vasto o campo de estudos sobre as práticas pedagógicas e da Educação para as Relações Étnico-raciais, de modo que, para efeito do presente artigo, circunscrevemos às relações étnico-raciais ao campo da afrodescendência, focalizando as práticas pedagógicas das(os) docentes da área de Letras-Português, mais notadamente aquelas empreendidas no ensino de Língua Portuguesa - doravante, LP —, como língua materna.

Em tal caso, propomos como questão norteadora a seguinte indagação: Quais as condições necessárias a uma prática pedagógica antirracista da(o) docente de LP, desde uma perspectiva educacional, para as relações étnico-raciais? Assim, objetivamos ao exame das relações possíveis entre racismo linguístico e as práticas pedagógicas da(o) docente de LP, com vistas à amenização e/ou superação dos mecanismos raciolinguísticos de exclusão no âmbito escolar.

Para efeito deste debate, entenda-se prática antirracista como toda prática pedagógica que, tendo sido articulada de forma crítica, proporciona às(aos) sujeitas(os) uma reflexão, de forma a ressignificar as experiências de relações múltiplas da diferença e da racialização, levando à resistência às ideologias e práticas discriminatórias, sendo, deste modo, pautada no compromisso com uma formação cidadã e inclusiva (GOMES, 2015). Entenda-se também mecanismos raciolinguísticos de exclusão como todo aparato ideológico-político pelo qual a diferença racial atua no plano da lingua[gem], silenciando as(os) sujeitas(os) racializadas(os) à medida que estigmatiza e tolhe sua variação linguística (NASCIMENTO, 2019).

O agenciamento das práticas pedagógicas por parte dessas(es) professoras(es) de LP, enquanto resposta antirracista ao ensino escolar que estabelece ao centro mecanismos raciolinguísticos de exclusão, traz a possibilidade de uma ação pedagógica que oportunize às(aos) educandas(os) um processo de ensino-aprendizagem inclusivo e cidadão.

De forma a atender à problemática e ao objetivo delineado, optamos pela pesquisa qualitativa, do tipo descritivo-explicativa. Para a produção de dados, priorizamos a entrevista narrativa. Delimitamos como sujeitas(os) da presente pesquisa 2 professoras(es) de LP do Ensino Médio da rede pública de ensino de Teresina-PI. Neste sentido, o corpus da pesquisa constitui-se de narrativas em torno da prática pedagógica desenvolvida por essas(es) professoras(es). A análise de dados priorizará, em conformidade à natureza da pesquisa, a técnica qualitativa, sendo de cunho analíticointerpretativo, orientado por um aporte teórico decolonial, com viés comparado, isto é, confrontar-se-á as duas perspectivas apresentadas pelas(os) professoras(es) 
MELO, L. A. N. de; MIRA, A. P. V. J. de

entrevistadas(os). Neste sentido, pretendemos, a partir das e com as narrativas em torno das práticas pedagógicas das(os) docentes de Letras-Português entrevistadas(os), refletirmos sobre as experiências racializadas de ensino de LP, de modo a deduzirmos condições e estratégias possíveis a um ensino de LP antirracista.

RACISMO LINGUÍSTICO E O ENSINO DE LÍNGUA PORTUGUESA: INTERROGANDO AS PRÁTICAS PEDAGÓGICAS DA(O) DOCENTE DE LETRAS

Para podermos refletir acerca das práticas pedagógicas da(o) docente de LP, cabe-nos, ainda que de forma concisa, historicizá-las neste primeiro momento, de forma a situá-las não apenas no debate no campo, mas, em sentido mais estrito, em nossa argumentação. Para tal devemos partir do pressuposto teórico de que, historicamente, o ensino-aprendizagem de LP no Brasil está diretamente condicionado a uma política de colonização linguística e, por conseguinte, a um processo de racialização. Mariani (2004) define colonização linguística como um sistema de controle e opressão, o qual se daria pelo

[...] estabelecimento de políticas linguísticas explícitas como caminho para manter e impor a comunicação com base na língua de colonização. Delimitando os espaços e as funções de cada língua, a política linguística dá visibilidade à já pressuposta hierarquização linguística e, como decorrência dessa organização hierárquica entre as línguas e os sujeitos que as empregam, seleciona quem tem direito à voz e quem deve ser silenciado. A formulação e execução de uma dada política linguística, no entanto, não impede totalmente a circulação e o amalgamento das línguas e dos sentidos. (MARIANI, 2004, p. 31).

Os principais agenciadores desse processo de colonização linguística foram, durante os primeiros séculos de ocupação, os padres jesuítas. $O$ ensino de LP e sua consequente institucionalização esteve, portanto, atrelado a um projeto pedagógicolinguístico de catequização de indígenas e negras(os) ${ }^{2}$, no qual as práticas pedagógicas desenvolvidas objetivavam a expansão do catolicismo, à época ameaçado pela Reforma Protestante, mediante a subalternização, dominação e exploração dessas(es) sujeitas(os). Esse processo de institucionalização da LP no Brasil através do ensino jesuítico teve, segundo Mariani (2004), como principais instrumentos a gramática normativa e os dicionários monolíngues e bilíngues.

Conforme a autora, o uso de gramáticas e dicionários no ensino regular de LP permitiu ao colonizador cristalizar, no imaginário colonial, a ficção de uma homogeneidade linguística, que visava, sobretudo, assegurar a superioridade cultural da metrópole portuguesa diante das(os) sujeitas(os) colonizadas(os), ao impor a LP como única língua possível. Porém, é verdade que durante esse primeiro momento o ensino da língua geral - um tupi gramaticalizado - ocupou lugar de destaque ao lado da língua europeia, que, no entanto, logo foi suprimida pela política linguicida do Marquês de Pombal. A partir daí, as políticas linguísticas de colonização, mediante uma homogeneização, passaram a se tornar mais acentuadas.

Apesar do acirramento dessas práticas linguicidas por parte da Metrópole colonial, línguas indígenas e africanas resistem, e ao lado da LP são concorrentes à 
produção de sentidos e às práticas sociocomunicativas, cada qual reportando a uma cosmovisão particular, dentro dos limites situados pelo embate. Seria, contudo, demasiado extemporâneo abordar toda a complexidade desse "convívio-confronto" no qual se enredam múltiplas histórias e interesses diversos. Basta se dizer que apesar da tentativa de sufocamento desses falares, eles continuaram coexistindo ao lado da LP durante séculos (cf. PESSOA DE CASTRO, 2005; BONVINI, 2014).

Neste sentido, seria inverossímil supor que o forte multilinguismo vivenciado no Brasil não deixou nenhuma marca, que as centenas de línguas indígenas — hoje não chegam a 200 - e africanas desapareceram sem deixar traço, sendo legadas ao anonimato e ao esquecimento reservados à condição de "línguas mortas", vítimas da política linguicida do colonialismo europeu. Dessa forma, as línguas negro-africanas transplantadas para o Brasil não desapareceram simplesmente, mas passaram de línguas plenas a línguas de intercurso, estando circunscritas à terminologia religiosa e às denominadas línguas secretase línguas de santo, sendo de exclusivo uso ritualístico nos terre[i]ros de umbanda e candomblé.

Petter (2005, p. 194) afirma que as línguas negro-africanas aparecem nos cânticos, saudações, nos nomes dos iniciados e dos adeptos, podendo, além disso, servir como veículo de comunicação entre os membros da mesma comunidade religiosa. $A$ fala empregada muitas vezes remete a estruturas próprias de pidgins. A autora ainda comenta que a aquisição desse código verbal está circunscrita aos iniciados, a quem o "acesso ao universo linguístico negro-africano" se dá paulatina e concomitantemente à imersão nos mistérios da fé.

No entanto, há de se frisar que, na dimensão linguística, os avanços têm sido muito tímidos e o problema da racialização da língua tem sido ignorado pelas(os) educadoras(es) da área de Letras-Português. É neste sentido que Lucchesi (2009) afirma que:

\footnotetext{
No plano linguístico, a contribuição dos segmentos indígenas e africanos para a formação da realidade linguística brasileira tem sido negada, ora por razões ideológicas, determinadas por uma visão de "superioridade cultural" do colonizador europeu, ora por opções teóricas imanentistas, que circunscrevem à lógica interna do sistema linguístico às dificuldades de realizar pesquisas de campo que possam recolher evidências empíricas consistentes da ocorrência no português brasileiro de processos de variação e mudança efetivamente induzidos pelo contato entre línguas, de modo que subsistem a lacuna acerca do real papel dos segmentos indiodescendentes e afro-brasileiros na história linguística do país (LUCCHESI, 2009, p. 27).
}

Esse negacionismo está diretamente ligado àquilo que Nascimento (2019) denomina de racismo linguístico ${ }^{3}$. Ao falarmos em racismo linguístico é natural que a primeira indagação que se formule seja: uma língua tem cor? Ora, as línguas não existem em si, nem por si mesmas, não são dados objetivos da natureza; ao contrário, elas são sociohistoricamente constituídas e estão profundamente atreladas ao mundo humano como um fenômeno sociocultural. As(os) próprias(os) sujeitas(os) situadas(os) 
MELO, L. A. N. de; MIRA, A. P. V. J. de

geohistoricamente por trás destas línguas por muitas vezes estão localizados numa posição racializada. E é neste sentido que Nascimento (2019) afirma que

[...] nenhuma língua tem cor porque nenhuma língua existe em si. Entretanto, ao serem politizadas, as línguas têm cor, gênero, etnia, orientação sexual e classe porque elas funcionam como lugares de desenhar projetos de poder, dentre os quais o próprio colonialismo fundado a partir de 1492 e a colonialidade que ainda continua entre nós como continuidade dele (NASCIMENTO, 2019, p. 21-22).

Para o autor, as línguas não apenas possuem uma cor quando politizadas nos mais diversos sistemas de poder, como também funcionam como locus de disputa racializadora, pois é por meio dela que se nomeia, racializa, silencia e se nega às(aos) sujeitas(os), reduzindo-as(os) a uma outridade, e, consequentemente, é por meio dela que as(os) sujeitas(os) igualmente resistem ao racismo, à negação e reificação. A apropriação da língua enquanto agência a desumanização e discriminação pode ser percebida através daquilo que Gonzalez (1988) denomina de

[...] 'pretoguês' e que nada mais é do que marca de africanização do português falado no Brasil [...]. O caráter tonal e rítmico das línguas africanas trazidas para o Novo Mundo, além da ausência de certas consoantes [...] apontam para um aspecto pouco explorado da influência negra na formação histórico-cultural do continente como um todo (e isto sem falar nos dialetos 'crioulos' do Caribe)(GONZALEZ, 1988, p. 70).

O pretuguês é, portanto, nada mais que o vernáculo afrobrasileiro, e que se define, de um ponto de vista estrutural, por conservar em sua gramática algumas particularidades dos sistemas linguísticos africanos. A um nível morfossintático podemos observar: variação de número no sintagma nominal - morfema de plural /-s/ não incidente nos nomes e desconhecida das línguas africanas; variação de número no sintagma verbal; certo grau de instabilidade de gênero gramatical; formas específicas de realização de sujeito nulo; dupla negação; preferência pela próclise. A um nível fonológico podemos destacar: iotonização da palatal $/ K /$, estranha às línguas oesteafricanas; alternância da lateral /// com /r, n, t/, comuns ao quicongo e quimbundo ; primazia das vogais. E, ainda, ao nível lexical: aportes; decalques; e híbridos (cf. PESSOA DE CASTRO, 2005; LUCCHESI; BAXTER; RIBEIRO, 2009).

Todas essas marcas são algumas dentre as muitas que estão linguística, histórica e socialmente ligadas à fala das(os) sujeitas(os) afrodescendentes e, continuamente, são estigmatizadas, sendo vistas como meros desvios de linguagem e não como contributos africanos à formação da variação da LP falada no Brasil, resultantes de séculos de contato entre línguas, situações de multilinguismo e da concorrência entre gramáticas, característicos desse contexto sociohistórico, bem como das interferências delas resultantes nos diversos níveis de organização estrutural da língua.

Mas para compreendermos o pretoguês e seu lugar no ensino escolar devemos saber sê-lo, antes de tudo, resultante de um longo percurso marcado pela violência, pela objetificação, pelo trauma, pela cisão, pelo linguicídio e epistemicídio, pela disputa de 
sentidos e de lugares de enunciação, bem como também pela resistência através da apropriação e ressignificação da língua do colonizador; e, portanto, não deve ser interpretado apenas em seu aspecto estrutural. Ao formularmos essa proposição não pretendemos descartar, ou mesmo secundarizar, os importantíssimos contributos africanos à formação de sua gramática, mas evidenciar sua historicidade e sociabilidade, e os conflitos de poder que o permeiam em seus paradoxos, matizes e complexidades.

O pretuguês contemporaneamente situado no lugar de "convívio-confronto" tal como as línguas africanas e indígenas no período de colonização - tem sua relevância, no ensino escolar, minada. Nessa mesma esteira de pensamento Lucchesi (2011) afirma a existência de uma

[...] continuidade do colonialismo linguístico, pois, se a independência política do Brasil se encaminha para os seus 200 anos, a submissão linguística continua, e os gramáticos brasileiros ainda têm Portugal como uma verdadeira metrópole colonial. [...] Essa atitude de vassalagem linguística a Portugal não apenas revela um projeto nacional elitista e excludente, mas suas motivações racistas (LUCCHESI, 2011, p. 99).

Neste sentido, o ensino escolar brasileiro - ainda calcado unicamente numa perspectiva normativista, aos moldes da antiga política de colonização linguística — não produzirá nenhum avanço significativo para a superação do racismo linguístico e nem será capaz de questionar as violências que sustentam a hegemonia da variação padrão. Para desnaturalizar os mecanismos ideológicos do racismo linguístico é preciso que a(o) docente de Letras-Português demonstre às(aos) educandas(os) suas motivações históricas, políticas, sociais e econômicas, e evidencie que essas características gramaticais tão marcantes na fala das(os) sujeitas(os) afrodescendentes nada mais são do que contributos africanos - e indígenas - e nada, em absoluto, tem a ver com um dado nível de escolarização ou mesmo com uma [in]capacidade comunicativa. E se elas são, por outro lado, estigmatizadas, é porque são racializadas e não porque, de um ponto de vista linguístico e comunicativo, sejam menos elaboradas que aquelas da variação dita padrão ou porque constituiriam qualquer tipo de agramaticalidade. E que, para além disso, o pretuguês, enquanto vernáculo afrobrasileiro, não tem seu uso circunscrito aos afrodescendentes, mas que ele é, por outro lado, o próprio português brasileiro, permeando até mesmo a fala da branquitude elitista que tanto a despreza e a vilipendia, como muito bem observa Gonzalez (1983) no excerto a seguir:

É engraçado como eles gozam a gente quando a gente diz que é Framengo. Chamam a gente de ignorante dizendo que a gente fala errado. [...] Ao mesmo tempo, acham o barato a fala dita brasileira, que corta o erres dos infinitivos verbais, que condensa você em cê, o está em tá e por aí a fora. Não sacam que tão falando pretuguês (GONZALEZ,1983, p. 238).

Contudo, a falta de cursos de formação para professoras(es) e a ausência de materiais didáticos sobre a temática geram, em certa medida, uma cumplicidade entre a 
MELO, L. A. N. de; MIRA, A. P. V. J. de

educação escolar e o processo de silenciamento do pretuguês, deixando patente que os avanços curriculares obtidos nas últimas décadas, embora significativos, não se mostram suficientes face ao racismo linguístico. Se as(os) professoras(es) de LP não desenvolverem uma prática reflexiva em torno do problema da racialização, ou melhor, enquanto elas(es) não desenvolverem uma prática pedagógica antirracista e, portanto, inclusiva e questionadora, as inovações curriculares anteriormente elencadas à parte introdutória deste artigo tendem a ficar restritas às suas potencialidades, sem serem efetivamente operacionadas. É neste mesmo sentido que Nascimento (2019) apregoa que:

\begin{abstract}
O papel da educação deverá ser mais do que reflexiva. Deverá, assim, conduzir a uma visão que torne a ontologia do sujeito como seu encontro entre sua identidade e o mundo ao seu redor, que the racializa e lhe concede direitos ao passo que ele age no mundo. $O$ sujeito negro será aquele que, por causa das marcas em seu calo, saberá, portanto, compreender ao seu tempo quais armas deverá usar através da linguagem (NASCIMENTO, 2019, p. 113).
\end{abstract}

É patente que o ensino não se limita apenas à reflexão, que, apesar de capital, não é, por outro lado, suficiente. É preciso ir além e colocar ao centro a dimensão ontológica, ou para reportamo-nos a Fanon (2008), trazer para o ensino de LP a consciência de que falar é sumamente existir, e que privar a fala é relegar inexistência ao Ser, isto é, à(ao) educanda(o).

\title{
Procedimentos METODOLÓGICOS
}

Em conformidade ao problema e objetivos de pesquisa, adotamos uma abordagem decolonial, de modo que o "conhecimento e compreensão" acadêmicos devem ser completados pelo "aprender com" e não simplesmente pelo "aprender sobre" essas(es) sujeitas(os) que experienciam os legados coloniais a partir de suas vivências individuais e/ou coletivas (MIGNOLO, 2020). Diante disso, buscamos colocar as(os) professoras(es) como interlocutoras(es) ativas(os) no processo de investigação, de modo que optamos pela entrevista narrativa, pois entendemos que, primeiramente, nesse tipo de entrevista o grau de interferência do entrevistador-pesquisador é mínimo e, secundariamente, porque ele busca distanciar-se do modelo de entrevista estruturada, no que diz respeito ao esquema "pergunta-resposta", que condiciona a(o) entrevistada(o) a uma posição de passividade diante da(o) entrevistadora( ) (JOVCHELVITCH; BAUER, 2002).

Através deste instrumento pretendemos evidenciar, mediante a construção de narrativas pelas(os) professoras(es) entrevistadas(os), as tensões no campo, as dissonâncias e assonâncias que permeiam as disputas de sentido, fazendo emergir da experiência delas(es) os problemas do cotidiano em sala de aula, bem como as reflexões sobre, pelas e nas suas práticas pedagógicas, ordenados em torno do eixo que propusemos como recorte a esta investigação.

Jovchelovitch e Bauer (2002) definem como fases principais da entrevista narrativa: i) preparação: exploração do campo, formulação de questões exmanentes (roteiro); ii) iniciação: formulação do tópico inicial para narração, emprego de recursos 
visuais; ii) narração central: não interromper, encorajamento não-verbal ou paralinguístico para continuar a narração, esperar para sinais de finalização; iii) fase de perguntas: não se deve dar opiniões ou fazer perguntas sobre atitudes, não discutir sobre contradições, não fazer perguntas imanentes, iv) fala conclusiva: parar de gravar, fazer anotações imediatas.

Através desta interface entre uma abordagem narrativa e decolonial, pretendemos nos distanciar da visão cientificista do Ocidente cristão que reduz a subjetividade dessas(es) sujeitas(os) a mero objeto de estudo. De modo que a análise de dados - para utilizarmo-nos da terminologia ocidental - que segue, na qual deslocamo-nos entre os enredamentos dos relatos biográficos e as percepções que estas(es) sujeitas(os) têm dos fatos vividos, não objetivamos a uma produção de conhecimento, pois estas narrativas configurariam em si, como diz Mignolo (2020), uma forma de conhecimento. O que se busca, portanto, é uma organização e articulação entre o conhecimento acadêmico ou teórico e o conhecimento dessas(es) sujeitas(os), no sentido de suplantar algumas das lacunas da primeira. Dentre essas lacunas destacamos aquela cuja enunciação marca nosso problema de pesquisa.

Outro aspecto a ser destacado é que, respeitando as convenções éticas da pesquisa em Ciências Humanas e Sociais, os nomes das(os) sujeitas(os) da pesquisa não são expostos na redação do texto; contudo, reconhecendo, na esteira do pensamento decolonial, que a retirada do nome constitui, em suma, estratégia colonial que infringe a essas(os) sujeitas(os) uma violência epistemológica, não poderíamos seguir a orientação ética circulante na academia sem incorrer, paradoxalmente, num ato antiético. Num esforço modesto e em caráter provisório, buscamos contornar essa situação solicitando as(aos) entrevistas(os) que escolhessem por si mesmas(os) os pseudônimos sob os quais gostariam de ser identificadas(os) no âmbito da presente pesquisa. Nesse sentido, as(os) professoras(es) se auto-[re]nomearam Patrícia Lopes e Teseu.

PRÁTICAS PEDAGÓGICAS E EDUCAÇÃO PARA AS RELAÇÕES ÉTNICO RACIAIS NO ENSINO DE LP: DA PRÁTICA EXCLUDENTE À ANTIRRACISTA

Observar a prática docente quanto ao ensino de língua portuguesa e as relações étnico-raciais, pressupôs, desde o início dessa investigação acercar-nos das(os) sujeitas(os) investigadas(os). Para isso, traçamos, mesmo que de forma breve, seus perfis.

Perfil da(o) docente de LP

Buscando identificar e caracterizar o perfil de cada docente entrevistado(a) através da narrativa autobiográfica, solicitamos a cada sujeita(o) que relatasse sua trajetória profissional como docente de LP no âmbito do Ensino Médio de Teresina. Assim, obtivemos as seguintes narrativas:

Iniciei minha trajetória como professora substituta do Estado e, ao mesmo tempo, numa escola particular de médio porte. Logo em seguida, fui contratada por uma grande escola, na qual estou até 
MELO, L. A. N. de; MIRA, A. P. V. J. de

hoje, e em 2020 iniciei em uma outra escola também. Nessas duas últimas, tenho atuado essencialmente como professora de Redação (PATRÍCIA LOPES).

\begin{abstract}
Eu tenho vinte anos de sala de aula. Terminei minha graduação no ano 2000. Se hoje o currículo não contempla a questão da diferença, nessa época então nem se falava nisso. Era uma época em que a conclusão do curso nem exigia o chamado TCC. E eu iniciei os trabalhos dessa forma. Depois eu fiz uma especialização e depois eu entrei para o mestrado. Com relação ao Ensino Médio propriamente dito, já trabalhei nas três séries. Eu observo que nenhuma das três, dentro do ensino de Literatura, por exemplo, há uma preocupação em se falar ou se colocar dentro dos conteúdos programáticos essas habilidades, leituras, essas competências que são exigidas pela lei que agora vigora no que tange a Literatura Afro-brasileira, por exemplo. E no ensino de Gramática também não. Ainda, na minha opinião, continua sendo um ensino muito mecânico em que o professor em si é que fará a diferença se for de sua vontade, incluindo em sua programação a utilização de textos e abordagens que se voltem para essas temáticas (TESEU).
\end{abstract}

A partir das experiências narradas delineamos o perfil de cada docente de LP do Ensino Médio, do município de Teresina, Piauí, de modo que evidenciamos e analisamos as características do perfil das(os) professoras(os) entrevistadas(os). Nos enredamentos que constituem a tessitura da trajetória profissional da professora Patrícia Lopes percebe-se que a professora é graduada em Letras e possui considerável experiência com a docência. No entanto, percebe-se não haver menção à Educação para as Relações Etnicorraciais em sua formação, quer em nível de graduação ou formação continuada. Essa ausência assinala para um possível déficit no currículo de formação de professoras(es) de LP e indica uma via pela qual o racismo linguístico atua, no sentido de legitimar suas violências, ao institucionalizar a exclusão de aportes teóricometodológicos que possam subsidiar uma prática pedagógica antirracista, na esfera do ensino de LP; isto é, atua para se "camuflar", perpetuando-se.

Podemos identificar que, por outro lado, a narrativa do professor Teseu que destaca, em sua trajetória, os problemas, desafios e enfrentamentos das(os) docentes cuja formação é tributária de um currículo anterior às políticas públicas antirracistas que impõem a presença de disciplinas e da transversalidade do debate sobre a temática de africanidades e afrodescendência, assinalando a urgência da promoção de cursos de formação de professoras(es) que contemplem a problemática abordada.

Em agravo, o professor Teseu assinala para a inobservância de preceito da lei 11.639 de 2003, a qual determina que "Os conteúdos referentes à História e Cultura AfroBrasileira serão ministrados no âmbito de todo o currículo escolar, em especial nas áreas de Educação Artística e de Literatura e História Brasileiras" (BRASIL, 2003, grifo nosso), posto que os temas não são abordados em nenhuma das três séries do Ensino Médio, quer seja na Literatura, Gramática ou Redação. O que vem demonstrar a um só tempo as fragilidades de um currículo escolar sofrível no que tange à Educação para as Relações Etnicorraciais, bem como a falta de fiscalização por parte dos órgãos competentes no 
que se refere à superação do racismo linguístico e à promoção da inclusão e do respeito ao Diverso no âmbito escolar, conforme imposto por lei em âmbito nacional.

A não inclusão desses temas no conteúdo programático da disciplina deixa o debate sujeito à vontade das(os) professoras(os), as(os) quais podem, por negligência ou pelo déficit em sua formação, como já frisado, não abordar a questão, deixando uma grande lacuna que tende à manutenção das violências e discriminações em suas múltiplas expressões, mais notadamente neste artigo as de ordem raciolinguística.

Outro aspecto apontado pelo professor é que o ensino de Gramática ainda se dá aos moldes do paradigma estruturalista, priorizando, assim, a análise do sistema isolado de seu contexto social. Duas considerações devem ser feitas a partir daí. A primeira é que, ao dissociar língua e sociedade, ou seja, ao ignorar os usos concretos da língua, a(o) professora( ) priva as(os) suas(eus) educandas(os) de perceber que tais usos não são neutros, bem como de identificar e refletir sobre as relações de poder e os processos de racialização que atravessam a lingua[gem], isto é, de perceber racismo linguístico que atravessa os diversos atos comunicativos e, por conseguinte, priva-as(os) de pensar estratégias de superação a essa realidade. Pois, conforme afirma Nascimento (2019. p. 19): "o racismo é produzido nas condições históricas, econômicas, culturais e políticas, e nelas se firma, mas é a partir da língua que ele materializa suas formas de dominação".

A segunda é que, uma vez que o ensino de LP permanece "um ensino muito mecânico" (TESEU), o pretuguês não encontrará, dentro do espectro dessa abordagem, um lugar em sala de aula, salvo o lugar da estereotipação e da discriminação, sendo tomado como um conjunto de "erros". Neste caso, o racismo linguístico opera por meio da exclusão, ao preservar a política colonial de um ensino estrutural calcado na rigidez da gramaticalização e da homogeneidade linguística nela imbricada. Ao reproduzir, em sala de aula, a hierarquização racial por meio dos usos da língua, isto é, em que apenas a norma europeia (a gramática normativa) deve possuir um lugar (de prestígio) no ensino escolar, a(o) professora( ) constrói uma prática pedagógica racista e excludente.

Abordagem teórico-metodológica da(o) docente de LP

No segundo momento, cada professor passou a narrar como se dá o recorte, sistematização e operacionalização dos aportes teórico-metodológicos que embasam suas práticas pedagógicas antirracistas, enquanto docentes de LP no Ensino Médio.

Como professora de Redação, trabalho com gêneros textuais. No Ensino Médio, há o predomínio do texto dissertativoargumentativo, em que se argumenta acerca de um tema social. Dessa forma, tenho buscado inserir a temática acerca do racismo nas discussões e nas propostas de produção textual. Inclusive, usando minhas redes sociais como extensão desse trabalho: esse ano fiz lives com uma amiga que pode falar com mais propriedade por estudar o tema e ser preta. Tenho um canal no youtube, e gravei sobre o tema. Essa prática é complementar à sala de aula, já que uso minhas redes sociais para esse trabalho complementar. 
MELO, L. A. N. de; MIRA, A. P. V. J. de

Porém, em sala, sempre que possível, abordo o tema (PATRíCIA LOPES).

Eu tenho experiência tanto na rede privada quanto na rede pública. Eu presto serviço para a educação estadual há 20 anos. Eu tenho essa experiência na rede pública que me dá uma visão bem próxima do que é a realidade no que se refere a essa temática. Pra começo de conversa os livros didáticos eles não contemplam os estudos de textos, as abordagens dentro dos conteúdos que possa favorecer o estuda da temática da diferença, da discriminação, enfim. Essas temáticas ficam muito na dependência do professor em si. Então, no meu caso, qualquer gancho que eu tenha em uma aula expositiva ou num trabalho, numa apresentação eu vou tentar aproveitar pra trabalhar. Uma experiência interessante que eu tive há uns três anos quando eu comecei a pesquisar sobre Cristiane Sobral, que é a escritora que deu origem a minha dissertação. Eu levei para uma turma do segundo ano um conto de Cristiane Sobral chamado "Metamorfose" e pedi aos alunos que fizessem uma apresentação dramática desse conto. Foi uma experiência bem interessante, porque as alunas se identificaram com a protagonista, com relação a temáticas sobre o corpo negro, o cabelo, enfim. E foi possível abordar esse tema dentro deste estudo do conto. A princípio houve um desinteresse, mas eu insisti e acabou acontecendo a apresentação e isso despertou comentários e foi bem lucrativo, foi bem interessante até mais pra eles do que pra mim essa prática. Esse é um exemplo de prática metodológica. No que tange ao ensino de Gramática na rede pública não há uma separação; é um professor pra disciplina Língua Portuguesa, então esse mesmo professor vai trabalhar Produção de Texto, Gramática e Literatura. É possível até encaixar, e na minha opinião proveitosos, que encaixe uma mesma abordagem, um mesmo tema em uma mesma aula até as três áreas do conhecimentos. Então se por exemplo estudo um texto de Cristiane Sobral e dentro daquele texto eu vou trabalhar um termo, um grupo nominal que possa me permitir essas análises é muito interessante. Por exemplo, a protagonista de Cristiane Sobral diz que "gasta uma grana preta" para cuidar do cabelo, que lá é um alisamento, e a narradora faz lá uma reflexão: "Grana preta? Porque não seria grana branca já que é tão valorizada?" Então, é como se ela andasse na contramão que os termos costumam fazer no que se refere ao "preto", que é depreciativo. Então aí nesse ponto eu já encontro um gatilho para trabalhar com os alunos, dentro dessa metodologia, essa temática. Esse é um exemplo de prática que eu já abordei, que é possível fazer (TESEU).

A professora Patrícia Lopes assinala para a legitimidade e relevância do debate ao afirmar que "sempre que possível, abordo o tema" (PATRíCIA LOPES). Neste sentido, a professora abre o campo para a possibilidade de enfrentamento, ao proporcionar um debate sobre o racismo através da reflexão pela redação de texto dissertativoargumentativo. Neste sentido, a língua[gem] surge, em sua modalidade escrita, como agência à racialização, a partir, sobretudo, da potencialidade de uma escrevivência por 
parte das(os) educandas(os). O conceito de escrevivência, cunhado por Conceição Evaristo (2007), assinala a noção ou consciência que "compromete a minha escrita como lugar de autoafirmação das minhas particularidades, de minhas especificidades" (EVARISTO, 2007, p. 20, grifos nosso), fugindo, porquanto, às generalizações, reducionismos e essencialismos próprios à racialização, ou seja, é ferramenta e estratégia profícua de combate aos estereótipos, cuja apropriação por parte das(os) alunas(os) que ocupam lugares racializados marca um avanço significativo no ensino.

Nascimento (2019) frisa que o racismo linguístico traz em seu bojo uma relação intrínseca entre epistemicídio e linguicídio. Segundo o autor "o epistemicídio é linguicídio quando desapropria o sujeito de seu próprio direito de produção do saber. Ou seja, quando ao sujeito negro ou indígena é negada a possibilidade de ser sujeito da língua" (NASCIMENTO, 2019, p. 26). Assim, ao possibilitar a reflexão através do texto, coloca ao centro do processo de ensino-aprendizagem a(o) educanda(o) como sujeita(o) da língua. Nisto se recupera a humanidade da(o) própria(o) aprendente, a qual é alienada pelo racismo linguístico, uma vez que este interdita sua condição de Sujeito, isto é, a condição humana.

É importante frisarmos na fala da professora Patrícia Lopes a importância de que o debate não se limita apenas à sala de aula - embora o foco deste artigo seja a análise das práticas pedagógicas desenvolvidas no ambiente escolar. Entendemos que a produção desse tipo de conteúdo nas redes sociais - principalmente no período em que vivemos, no qual os discursos de ódio e negação da ciência se propagam rapidamente nas redes - é capital para o debate, uma vez que opera como mais uma fonte de interação e pesquisa para educandas(os) que buscam aprender mais sobre e demais professoras(es) que buscam estratégias de como abordar o tema e seus subtemas em sala de aula. Pode-se inferir ainda que a busca por outros espaços para articulação vem demonstrar que o espaço escolar não se mostra um lugar suficiente para operar essa reflexão, o que é uma constatação preocupante e sintomática de um ensino alheio - e por omissão, conivente - ao problema da racialização e do racismo, notadamente, neste artigo, o racismo linguístico.

Podemos constatar através da fala do professor Teseu que, apesar da determinação por vasta legislação (BRASIL, 2003; 2004; 2008; 2014), os livros didáticos estão em desconformidade com a norma prevista, e não abordam os conteúdos concernentes a africanidades, afrodescendência, racismo e racialização. O livro didático, enquanto artefato próprio da cultura escolar, dá testemunho, mediante a narrativa do professor, da ausência de uma efetiva sensibilidade à Educação para as Relações ÉtnicoRaciais e, em última análise, a ausência de cautela e observância por parte das editoras e do poder público ao que concerne o cumprimento da Lei.

Neste sentido, o professor Teseu chama à seara a necessidade de uma adequação, por parte da(o) docente, do conteúdo programático da disciplina de LP, no sentido de tentar contribuir em certa medida para o desenvolvimento de uma racionalidade crítico-reflexiva por parte das(os) educandas(os) no que tange às relações étnico-raciais, os aspectos de racialização e racismo a partir, sobretudo, de um diálogo com o exposto na disciplina e a realidade individual e coletiva do alunado. 
MELO, L. A. N. de; MIRA, A. P. V. J. de

Deste modo, para subsidiar sua abordagem teórico-metodológica, o professor Teseu recorre aos conhecimentos que tem sobre a temática, sobretudo àqueles concernentes a sua dissertação sobre a literata negra Cristiane Sobral. Partindo disso, o professor elabora uma estratégia lúdica de ensino, na qual se insere a leitura de Literatura Afro-brasileira a partir da dramatização. Tal abordagem permite uma apropriação do texto literário como forma significativa de reflexão a partir do estreitamento das relações das(os) alunas(o)s com a trama, o que é propiciado pela encenação: "as alunas se identificaram com a protagonista, com relação a temáticas sobre o corpo negro, o cabelo" (PROFESSOR TESEU). Isso possibilita um diálogo profícuo entre a diegese e a exegese, articulando as problemáticas de gênero (genderização) e raça (racialização), permitindo um exame crítico acerca de como essas duas categorias perpassam os domínios da língua[gem], em uma relação interseccional; complexificando, deste modo, a própria percepção de racismo linguístico em suas dinâmicas de violência, isto é, possibilita uma compressão de como os mecanismos linguísticos de exclusão e estigmatização assumem estratégias particulares em se tratando da mulher negra. Além disso, a atividade, por seu cunho participativo, desloca as(os) educandas(os) para o protagonismo do processo de ensino, permitindo a interação e troca de experiências entre essas(es) sujeitas(os) à medida que se identificam com as personagens e tomam ciência de sua própria condição. Isso permite uma resistência conjunta, e cria, em certa medida, mas não em termos absolutos, dada as suas complexidades, uma sororidade entre elas(es).

Assim, a língua[gem] se reinventa, transgride o quadro previsto e se torna um espaço antirracista, contra-hegemônico. Para citar bell hooks: "Nós fazemos das nossas palavras uma fala contra-hegemônica, liberando-nos nós mesmos na linguagem" (HOOKS, 2008, p. 863-864). Assim, a partir do exercício proposto a(o) aprendente é colocado como sujeita(o) da língua, que se vale da língua[gem] como agência na construção de experiências, de vivências e de práticas antirracistas, apresentando-se com uma estratégia pedagógica possível de enfrentamento ao racismo linguístico.

Apesar disso, o pretuguês não ganha destaque em nenhuma das abordagens e o tema da racialização da língua[gem] evocado pelo conceito de racismo linguístico, de Nascimento (2019), parece longe de penetrar na sala de aula, apesar do esforço empreendido pela(o) professora( ), no sentido de adequar os conteúdos, fazendo diálogo com os temas e problemas a ele atinentes.

\section{CONSIDERAÇÕES FINAIS}

A partir das experiências trazidas pelos docentes, inferimos a necessidade de: repensar as políticas editoriais e públicas acerca dos livros didáticos, em adequação à legislação; reorganizar o currículo escolar de forma a inserir efetivamente as temáticas sobre africanidades, afrodescendência e racialização nos conteúdos programáticos do Ensino Médio; reestruturar, considerando-se a interlocução entre entrevistadas(os) e o paradigma decolonial, as políticas de currículo dos cursos de formação de professoras(es).

A falta de cursos de formação para professoras(es) ${ }^{5}$ e a ausência de materiais didáticos sobre a temática geram, em certa medida, uma cumplicidade entre a educação escolar e o processo de silenciamento do pretuguês, deixando patente que os avanços 
curriculares obtidos nas últimas décadas, embora significativos, não se mostram suficientes face ao racismo linguístico uma vez que os currículos escolares efetivamente não trazem temáticas correlatas, estando sujeitas à adequação por parte das(os) professoras(es), que não receberam formação adequada para tal.

Se as(os) professoras(es) de LP não desenvolverem uma prática reflexiva em torno do problema da racialização, ou melhor, enquanto eles não desenvolverem uma prática pedagógica antirracista, a exemplo das(os) professoras(os) entrevistadas(os), e, portanto, inclusiva e questionadora, as inovações curriculares anteriormente elencadas na parte introdutória deste artigo tendem a ficar restritas às suas potencialidades, sem serem efetivamente operacionadas.

É necessário que o ensino não se limite apenas à reflexão, que apesar de capital, não é, por outro lado, suficiente. É preciso ir além e colocar ao centro a dimensão ontológica, ou, para reportamo-nos a Fanon (2008), trazer para o ensino de LP a consciência de que falar é sumamente existir, e que privar a fala é relegar inexistência à(ao) educanda(o).

Artigo recebido em: 20/02/2021

Aprovado para publicação em: 14/10/2021

THE PRETUGUESSIN THE CLASSROOM: LINGUISTIC RACISM AND THE PEDAGOGICAL PRACTICES OF THE PORTUGUESE LANGUAGE TEACHER

ABSTRACT: This article addresses the theme of teaching pedagogical practices to combat racism in Portuguese language classes. Thus, we aim to examine the possible relationships between linguistic racism and the pedagogical practices of the Portuguese-speaking teacher, with a view to easing and / or overcoming raciolinguistic exclusion mechanisms in the school environment. From the objective outlined, we opted for qualitative research, of the descriptive-explanatory type, with a narrative approach, with a decolonial bias. The intended discussion points to the need to rethink editorial and public policies about textbooks; reorganize the school curriculum in order to effectively insert the themes of Africanities, Afro-descent and racialization in the syllabus of high school and restructure the curriculum policies of Portuguese-speaking teacher training courses. Because such gaps generate an complicity between school education and the process of silencing the pretuguese. The discussion also highlights the need for teachers to develop a reflexive and ontological pedagogical practice around the problematic of linguistic racism.

KEYWORDS: Education for Ethnic-racial Relations. Pedagogical Practices. Pretuguese. Linguistic Racism. EL PRETUGUÊS EN EL AULA: EL RACISMO LINGÜÍSTICO Y LAS PRÁCTICAS PEDAGÓGICAS DE LA
(DEL) PROFESORA ( ) DE LENGUA PORTUGUESA 
MELO, L. A. N. de; MIRA, A. P. V. J. de.

RESUMEN: El presente artículo discute el tema de las prácticas pedagógicas docentes para el combate al racismo en las clases de Lengua Portuguesa. Así objetivamos examinar las relaciones posibles entre racismo lingüístico y las prácticas pedagógicas de la (del) profesora( ) de Lengua Portuguesa, con mirada a la amenización y/o superación de los mecanismos de exclusión raciolingüísticos en el ámbito escolar. Por el objetivo delineado, optamos por la investigación cualitativa, de tipo descriptivo explicativo, con un abordaje narrativo, de perspectiva decolonial. La discusión pretendida apunta para la necesidad de repensarse las políticas editoriales y públicas acerca de los libros didácticos; reorganizar el currículo escolar de forma a inserir efectivamente las temáticas sobre africanidades, afro descendencia y racialización em los contenidos programáticos de la secundaria y reestructurar las políticas de currículo de los cursos de formación de profesores de Lengua Portuguesa. Pues tales lagunas generan una complicidad entre la educación escolar y el proceso de silenciamiento del pretugués. La discusión también señala la necesidad de que las(los) profesoras(es) desarrollen una práctica pedagógica reflexiva y ontológica en torno al problema del racismo lingüístico.

PALABRAS CLAVES: Educación para las Relaciones Étnico Raciales. Prácticas Pedagógicas. Pretugués. Racismo Linguístico.

\section{NOTAS}

1 - O predomínio do masculino sobre o feminino nas marcações de plural e nas generalizações (indicação de uma categoria, ex.: "docente") ou mesmo o propor-se daquele a esse (ex.: "aluno(a)") reproduz a hierarquização social entre os gêneros através da estrutura da língua, revelando-nos "a problemática das relações de poder e a violência na língua portuguesa" (KILOMBA, 2019, p. 16); pelo que se opta, epistemológica e politicamente, pela presente forma de marcação de gênero, como uma maneira provisória de tentarmos minimizar esse quadro de violência que se interseccionaliza com o racismo linguístico, conforme exporemos na seção 4 intitulada Práticas pedagógicas e educação para as relações étnico raciais no ensino de $L P$ : da prática excludente a antirracista. Vale ressaltarmos, ainda, que a instabilidade de gênero gramatical é característica morfológica do pretuguês (cf. PESSOA DE CASTRO, 2005; LUCCHESI; BAXTER; RIBEIRO, 2009) com a qual dialogamos, por meio dessa grafia, ao longo do presente artigo.

2 - Devemos frisar que, quando nos reportamos à educação ou escolarização de indígenas e negras(os) escravizadas(os), alforriadas(os) e/ou ingênuos(os), estamos referindo-nos ao ensino de Primeiras Letras, pois o ensino Secundário era proibido a essas(es) sujeitas(os); e em casos mais comuns até mesmo o ensino de Primeiras Letras era completamente vedado às(ao) sujeitas(os) negras(os), tendo apenas os indígenas acesso à escolarização básica.

3 - A escolha teórica por racismo linguístico, em detrimento da noção operatória de preconceito linguístico - como conceito circulante no campo ao se examinar às relações linguísticas de opressão e discriminação - se dá por compreendermos que: (i) o preconceito linguístico não se mostra suficiente, uma vez que focaliza um recorte exclusivamente classista, ignorando a dimensão racializada das relações linguísticas de poder, bem como o peso epistemológico e axiológico do constructo moderno/colonial de raça - racialização - na configuração do [pós]moderno imaginário ocidental sobre as línguas e seu processo de institucionalização — no qual frisamos o ensino escolar -; e, ainda, que (ii) o preconceito linguístico denota um juízo de valor formulado a priori, e que não possui razão de ser, sendo atrelado a uma disputa de classes, enquanto o racismo linguístico, por outro lado, constitui-se como um sistema de opressão que nega a variação das(os) sujeitas(os) negras(os), silenciando-as(os) na exata medida em que as(os) situa na outridade e na diferença. Sublinhamos também que o racismo linguístico não exclui a 
variante classe social, mas acresce ao debate a variante racialização, problematizando, assim, aspectos até então alheios ao campo do ensino de LP.

4 - Línguas africanas pertencentes ao subgrupo banto, que foram massivamente faladas no Brasil até o primeiro quartel do século XX.

5 - Neste sentido é que o Núcleo de Pesquisa Sobre Africanidades e Afrodescendência da UFPI (IFARADÁ) tem promovido anualmente, a nível de extensão, um curso intitulado Introdução à Linguística Africana, focalizando a capacitação de professoras(es) e graduandas(os) das diversas licenciaturas, mais especificamente das áreas de Letras - em suas diversas habilitações Pedagogia, História e Sociologia. Além da proposta teórico-pedagógica deste curso, desenvolvese concomitante a ele pesquisas de campo em comunidades quilombolas e em terreiros de umbanda e candomblé do Piauí, cujos resultados são apresentados no Seminário de Linguística Africana da UFPI. Toda a referida programação integra o Programa de Extensão intitulado Uhuru (do suríli, língua africana, liberdade), coordenado pelo Prof. Dr. João Evangelista das Neves Araújo (UFPI-CCE/DEFE/İFARADÁ) e pelo Prof. Mestrando Lucas Anderson Neves de Melo (UFPIPPGEL/İFARADÁ).

\section{REFERÊNCIAS}

BRASIL. Lei 10.639/2003. Altera a Lei $\mathrm{n}$-9.394, de 20 de dezembro de 1996. Estabelece as diretrizes e bases da educação nacional, para incluir no currículo oficial da Rede de Ensino a obrigatoriedade da temática "História e Cultura Afro-Brasileira", e dá outras providências. Disponível em: http://www.planalto.gov.br/ccivil_03/leis/2003//10.639.htm Acesso em: 10 dez. 2020.

BRASIL. Resolução no 1, de 17 de junho de 2004. Diretrizes Curriculares Nacionais para a Educação das Relações Étnico-Raciais e para o Ensino de História e Cultura AfroBrasileira e Africana. Disponível em:

http://portal.mec.gov.br/dmdocuments/cnecp_003.pdf. Acesso em: 12 fev. 2021.

BRASIL. Lei 11.645/2008. Altera a Lei no 9.394, de 20 de dezembro de 1996, modificada pela Lei $n^{\circ}$ 10.639, de 9 de janeiro de 2003, que estabelece as diretrizes e bases da educação nacional, para incluir no currículo oficial da rede de ensino a obrigatoriedade da temática "História e Cultura Afro-Brasileira e Indígena". Disponível em: http://www.planalto.gov.br/ccivil_03/_ato2007-2010/2008/lei/l11645.htm. Acesso em: 12 fev. 2021.

BRASIL. Lei n. 13.005/2014. Aprova o Plano Nacional de Educação - PNE e dá outras providências. Disponível em: http://www.planalto.gov.br/ccivil_03/_ato20112014/2014/lei/l13005.htm. Acesso em: 12 fev. 2021.

BONVINI, E. Línguas africanas e o português falado no Brasil. In: FIORIN, J. L.; PETTER, M. (Orgs.). África no Brasil: a formação da língua portuguesa. São Paulo: Contexto, 2009. p. 15-62. 
MELO, L. A. N. de; MIRA, A. P. V. J. de

EVARISTO, C. Da grafia-desenho da minha mãe, um dos lugares de nascimento de minha escrita. In: ALEXANDRE, M. A. (Org.). Representações performáticas brasileiras: teorias, práticas e suas interfaces. Belo Horizonte: Mazza Edições, 2007, p. 16-21.

FANON, F. Pele negra, máscaras brancas. Trad. Renato da Silveira. Salvador: EDUFBA, 2008.

GOMES, A. B. S. A pedagogia do movimento negro em instituições de ensino em Teresina, Piauí. Teresina: EDUFPI, 2015.

GONZALEZ, L. Racismo e sexismo na cultura brasileira. In: SILVA, L. A. et al. Movimentos sociais urbanos, minorias e outros estudos. Brasília: ANPOCS, 1983, p. 223-244.

GONZALEZ, L. A categoria político-cultural de amefricanidade. In: Tempo Brasileiro. Rio de Janeiro, n. 92/93, p. 69-82, jan./jun., 1988.

HOOKS, B. Linguagem: ensinar novas paisagens/novas linguagens. In: Estudos Feministas. Florianópolis, p. 857-864, set./dez. 2008.

JOVCHELOVICH, S.; BAUER, M. W. Entrevista Narrativa. In: BAUER, M. W.; GASKELL, G. Pesquisa qualitativa com texto, imagem e som: um manual prático. Petrópolis: Vozes, p. 90-113, 2002.

KILOMBA, G. Memórias da plantação: episódios de racismo cotidiano. Trad. Jess Oliveira. Rio de Janeiro: Cobogó, 2019.

LUCCHESI, D. A fala de comunidades remanescentes de antigos quilombos e os efeitos do contato entre línguas do português popular do Brasil. In: LIMA, M. A. F.; ALVES FILHO, F.; COSTA, C. de S. S. M. de. Colóquios Linguísticos: enfoques epistemológicos, metodológicos e descritivos. Teresina: EDUFPI, 2011, p. 93-124.

LUCCHESI, D.; BAXTER, A.; RIBEIRO, I. et al. O português afro-brasileiro. Salvador: EDUFBA, 2009.

MARIANI, B. Colonização linguística. Campinas: Pontes, 2004.

MIGNOLO, W. Histórias locais/projetos globais. Histórias locais/projetos globais. Trad. Solange Ribeiro de Oliveira. Belo Horizonte: Editora da UFMG, 2020.

NASCIMENTO, G. Racismo linguístico: os subterrâneos da linguagem e do racismo. Belo Horizonte: Letramento, 2019.

PESSOA DE CASTRO, Y. Falares africanos na Bahia - Um vocabulário afro-brasileiro. 2. ed. Rio de Janeiro: Academia Brasileira de Letras; Topbooks Editora, 2005.

PETTER, M. Línguas africanas no Brasil. Gragoatá, Niterói, n. 19, p. 193-217, 2. sem. 2005.

Inter-Ação, Goiânia, v.46, n.3, p. 1395-1412, set./dez. 2021. Disponível em: <http://dx.doi.org/10.5216/ia.v46i3.67796>. 
Lucas Anderson Neves de Melo: Mestrando pelo Programa de Pós-Graduação em Letras (PPGEL) da Universidade Federal do Piauí. Especialista em Língua Portuguesa e Literatura Brasileira pela Faculdade FAMART. Graduado em Letras Português-Francês e suas respectivas Literaturas pela Universidade Federal do Piauí (UFPI). Membro do Núcleo de Pesquisa em Africanidades e Afrodescendência (İFARADÁ) e membro do Grupo de Pesquisa Teseu, o Labirinto e seu Nome.

Orcid: https://orcid.org/0000-0002-8266-9634

E-mail: Inanderson95@smail.com

Ane Patrícia Viana José de Mira: Doutoranda em Educação (Unisinos). Mestra em Educação (Universidade La Salle). Especialista em Gramática e Ensino de Língua Portuguesa (UFRGS). Especialista em Coordenação Pedagógica (UCDB). Especialista em Educação Especial Inclusiva (UGF). Licenciada em Letras (Universidade La Salle). Licenciada em Pedagogia (Uninter). Atua como docente do curso de Pós-graduação em Gestão Escolar e Coordenação Pedagógica na Verbo Educacional e é professora de Língua Espanhola no Ensino Médio da rede privada de ensino em Porto Alegre e Canoas. Orcid: https://orcid.org/0000-0002-8175-8213

E-mail:ane.mira23@gmail.com

Este periódico utiliza a licença Creative Commons Attribution 3.0, para periódicos de acesso aberto (Open Archives Initiative - OAI). 